Journal of Machine Engineering, 2020, Vol. 20, No. 4, 5-27

ISSN 1895-7595 (Print) ISSN 2391-8071 (Online)

Received: 25 July 2020 / Accepted: 05 October 2020 / Published online: 29 November 2020

machine tool, thermal error, cooling system, effects, development

\author{
Martin MARES ${ }^{1 *}$ \\ Otakar HOREJS ${ }^{1}$ \\ Stepan FIALA ${ }^{1}$ \\ Lukas HAVLIK ${ }^{2}$ \\ Petr STRITESKY ${ }^{3}$
}

\title{
EFFECTS OF COOLING SYSTEMS ON THE THERMAL BEHAVIOUR OF MACHINE TOOLS AND THERMAL ERROR MODELS
}

\begin{abstract}
Today, cooling systems are increasingly applied to the structure of machine tools (MT). Unfortunately, to date there have been few efforts to precisely control these cooling systems, which inhibits the full utilisation of their potential to improve MT thermal behaviour (to reduce thermal errors). Moreover, the effects of cooling systems, especially the effects of cutting fluids, on thermal error compensation models are often omitted. This paper deals with the effects of fluid cooling systems on the thermal behaviour of MT and thermal error compensation models. It provides a detailed review of the state of the art, followed by the authors' recent research on these issues. Firstly, the sensitivity of thermal error compensation models based on transfer functions (TF) to modification of fluid cooling systems and cutting fluid presence is discussed. Secondly, gradient regulation of the cooling unit to improve MT accuracy is presented.
\end{abstract}

\section{INTRODUCTION}

MT for cutting operations will continue being an important segment of production resources despite the increasing use of other production technologies such as casting, forming and, more recently, 3D printing. This is particularly true in the case of high value-added production, where high levels of dimensional accuracy and surface quality of shaped parts are required, along with material homogeneity of the final product. However, machining production requires mastering process accuracy and stability as well as process energy efficiency and flexibility. Meeting all of these qualitative aspects within a single manufac-

\footnotetext{
${ }^{1}$ Research Center of Manufacturing Technology, Czech Technical University in Prague, Czech Republic

${ }^{2}$ Machine tool development, KOVOSVIT MAS Machine Tools, a.s., Czech Republic

${ }^{3}$ Machine tool development, TOSHULIN, a.s., Czech Republic

*E-mail: m.mares@rcmt.cvut.czh

https://doi.org/10.36897/jme/128144
} 
turing system remains challenging today. This adverse situation is largely caused by mutually conflicting relationships, where routine remedies taken to enhance the para-meters of one aspect of production often markedly deteriorate the parameters of other aspects.

MT thermal behaviour is a common factor of the majority of the conflicting relationships. For example, the geometric accuracy of MT, traditionally associated primarily with production quality and machine assembly and alignment, is also influenced by the ongoing thermal deformations of the MT structure. In addition, thermo-mechanical phenomena naturally relate to the entire kinematic chain, machine tool, tool, workpiece system, and thus influence the resulting workpiece accuracy [1]. Thus, avoiding thermally induced deviations in workpiece dimensions has become crucial.

Active cooling, symmetrically designed machine structures, temperature measurements, and real-time thermal error compensation models are already common practice. Since reconstruction is mainly feasible in the MT prototype stage and the accuracy of predictive FE models depends on precise boundary condition determination and huge computing times, thermal error compensation models (software compensation) along with adaptive heat flux control signify widely employed strategies to reduce the thermal errors of MT already employed in production lines.

Furthermore, fluid cooling systems are frequently used in MT design to temper components, as thermal influences induce geometric errors and deteriorate MT accuracy [2]. In particular, if MT components are thermally loaded by heat losses, they must be cooled to prevent thermal damages. Therefore, fluid cooling systems, as an inseparable part of most MT equipment, are an important factor with significant impacts on the resultant MT thermal errors. In [3], an overview of the latest research in the field of fluid elements in MT is presented. Fluid cooling systems impact both cooling effectiveness and thermal error reduction, as well as service friendliness, energy savings, thermal load reduction and costs. Mayr et al. [4] further discussed thermal issues in MT in connection with fluid cooling systems in a specialized review.

Fluid cooling circuit design largely affects MT accuracy. In Fig. 1 (left), the positioning error of a cooled linear axis is shown [5]. The positioning error is affected by "over cooling" the linear axes, as the MT uses one cooling circuit for all tempered components and the feed system is the first in view of the flow. In [5], a model developed by computing the amount of heat generated in the feed drive system using thermal TF is presented. The model is applied to adaptive control of the cooling circuit.

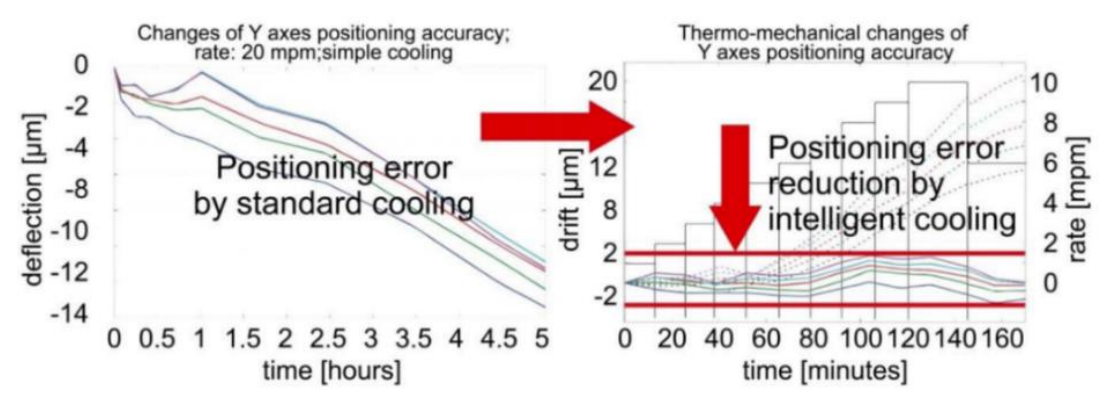

Fig. 1. Positioning error of a cooled linear axis with one cooling circuit; the system is "over-cooled" (left), positioning error reduction with adaptive control of the cooling circuit (right) [5] 
A significant reduction of thermal positioning errors induced by the feed drive is illustrated in Fig. 1 (right).

High traversing speeds and accelerations put a heavy load on the feed drives, causing heat to be generated. Without suitable position measuring technology, this rise in temperature can quickly lead to significant positioning errors. These errors are usually minimized using linear measurement systems. In order to increase stiffness and remove backlash of ball screws, preloading mechanisms have been used. Consequently, the applied preload on screw shaft produces more heat through bearing friction and potentially causes thermal variations [6]. Fluid cooling of a screw shaft and nut cooling are common contemporary solutions to prevent negative thermal effects of ball screws. If the cooling structure inside the nut is welloptimized, it can be achieved equivalent cooling capacity as hollow shaft cooling. A closed loop FEA of the cooled ball screw drive system is carried out to predict thermo-mechanical state in [6]. Presented FEM takes into account transient heat sources in bearings due to the coupling between the generated friction heat and the screw shaft axial force changes due to thermal deformation. FEM model and the programmed loop, consisting of thermal analysis followed by structural analysis is shown in Fig. 2. The developed FEM can be employed for evaluation of the designed cooling system in order to avoid failure of the ball screw system due to implied thermal stresses. The heat losses in the bearings are updated in accordance with the current thermo-mechanical state, see Fig. 2.

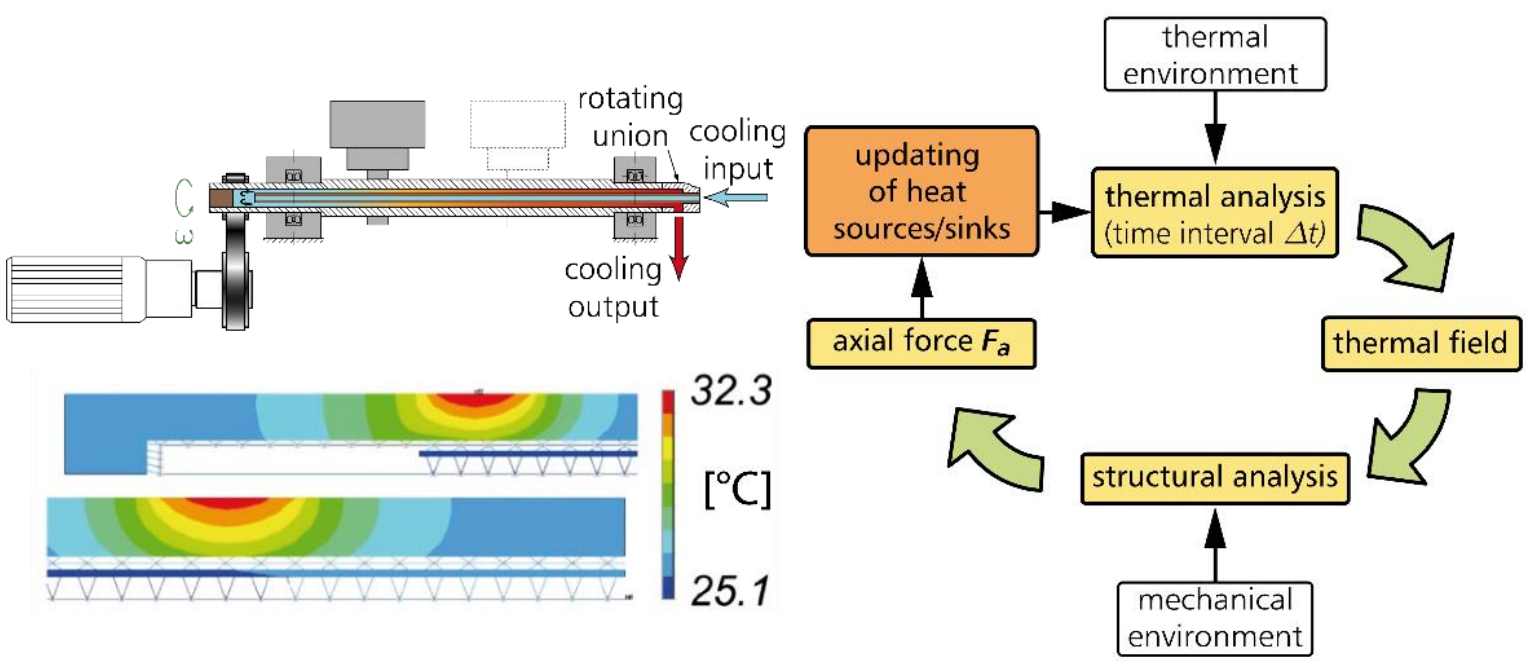

Fig. 2. Scheme of the simulation loop, consisting of thermal analysis followed by structural analysis [6]

The effects of fluid cooling systems of internal heat sources are related to the unstable and inconsistent intensity of a particular cooling circuit's action against the intensity of the relevant heat source. Hellmich et al. [7] showed that the dynamic changes in heat sources in the operating conditions of direct spindle drives require on-line monitoring and active control of the behaviour of the forced liquid cooling system to maintain the greatest possible cooling precision and to keep spindle displacements as low as possible.

Popken et al. [8] investigated the control concepts of different cooling system structures for MT and associated modelling. They focused on a cooling structure with a central variable 
speed drive unit in combination with proportional valves to distribute the flow rates, and on overcoming the over-determinacy of this cooling structure. Further investigation is necessary due to the cross-coupling of the system.

Application of temperature control in a high-performance large optics grinding machine with in-situ metrology capability was reported in [9]. To achieve thermal stability throughout the machine, a nine-channel temperature control system was developed. The temperature control approach in this case differs significantly from previous systems. Here a single cooling fluid is applied to different elements of the machine. The cooling capacity for each element is adjusted using proportional valves that control the flow rate. Each proportional valve is controlled by temperature measurements of the machine's sub-systems or process fluid. This temperature control approach enables a highly cost-effective solution to thermal management at $0.1 \mathrm{~K}$ control accuracy and provides a rapid level of control with a large cooling capacity.

Active control of a fluid cooling system based on TF is presented in [10] and [11]. The essence of active cooling control (ACC) is to remove/add a precise amount of heat from/to the structure in order to minimize the thermal error caused by non-stationary heat sources. The thermal error at the tool centre point (TCP) is generally unknown. Therefore, the thermal error must be first estimated from the main factors acting on the thermomechanical system (surrounding temperature, internal heat sources, etc.) using a TF model. If the goal is to minimize the thermal error, the cooling system must cause deformation, which is exactly opposite to the thermal error. This can be done with an IDTF $_{C}$ (inverse deformational transfer function of the cooling system), which enables recalculation of compensatory deformation into cooling (see Fig. 3). The terminology used for different types of TF according to their physical interpretation is described in [12].

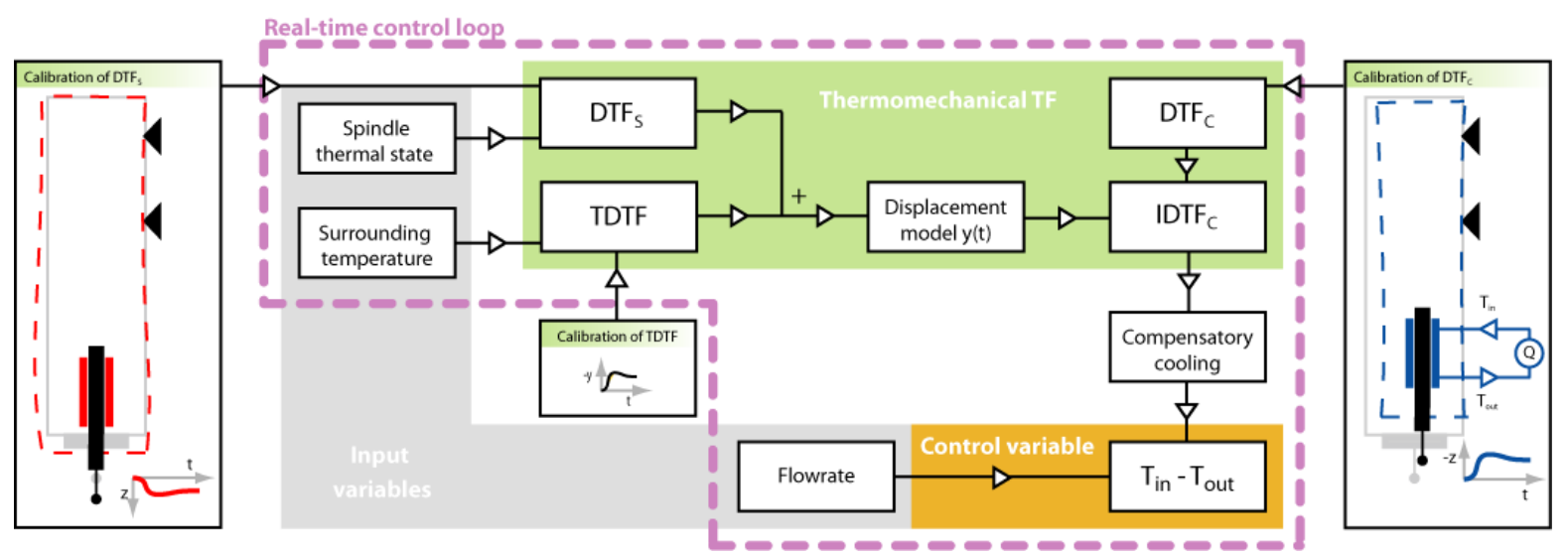

Fig. 3. Active cooling control scheme [10]

The ACC method was tested on a built-in cooling jacket of a CYTEC machine tool electrospindle (power $18 \mathrm{~kW}$, torque $70 \mathrm{Nm}$ and maximal revolution 15,000 rpm). The resultant residual MT thermal error remained within the range of $\pm 3 \mu \mathrm{m}, 2 \%$ of the maximum thermal error in the Z-direction, see Fig. 4. Since fluid cooling systems of internal heat sources have significant impacts on MT thermal behaviour and consequently resulting thermal errors at the TCP, they naturally affect thermal error compensation models as well. 

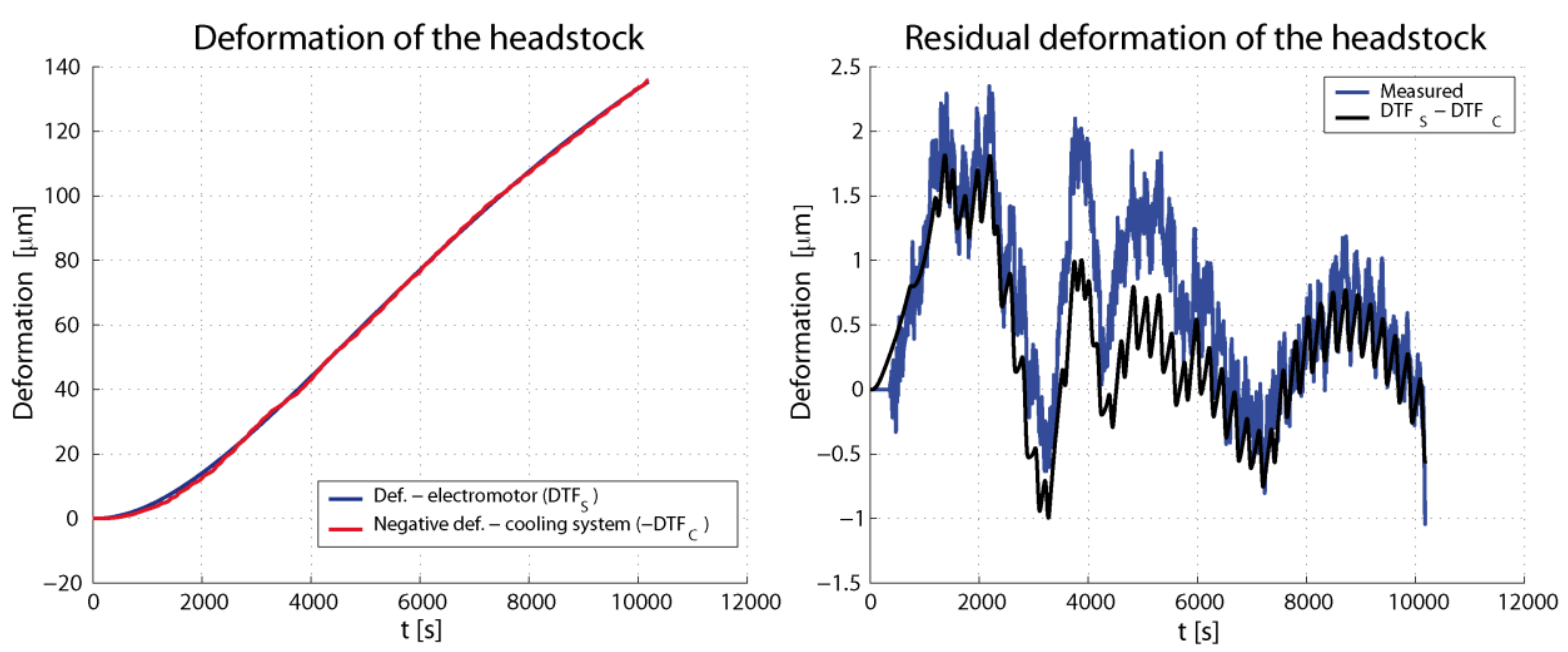

Fig. 4. Deformational balance (left), residual deformation - measured and calculated (right) [11]

A review of the literature shows that existing MT thermal simulation models (including thermal error compensation models) have mainly considered internal heat sources and thermal dissipation boundary conditions, but have rarely considered cutting fluid influences on thermal behaviour [13]. Cutting fluid is commonly used in flood cooling techniques, where a cooling jet is used to cool, lubricate, and remove chips generated during processing for the active zones. Thus, the cutting fluid absorbs a considerable amount of cutting heat and spatter on the machine bed, workpiece column, rotary table, and other components, resulting in a significant increase in thermal deformation. It has been shown in many applications that cutting fluid has a significant influence on the thermal behaviour of MT employing flood cooling techniques. Investigations in turning have shown that conventional coolants can significantly reduce the thermal error [14]. Use of a coolant has resulted in tool expansion reduction of over $80 \%$. However, recent efforts to encourage minimum quantity lubrication (MQL) do not take this effect on accuracy into account [15]. Chen [16] studied thermally induced MT errors in real cutting conditions. The results showed that the prediction accuracy of solely air cutting compensation models is unacceptable in real cutting applications. Thus, MT thermal error compensation methods should include cutting process effects to ensure robustness. This is because the cutting load and the cutting coolant applications produce significant thermal effects which are not taken into account by the air cutting approach. Mayr et al. [17] experimentally investigated the influence of cutting fluid on the overall thermal behaviour of a precise five-axis milling machine. The measured results proved that cutting fluid affects thermal behaviour strongly.

Generally, the effect of the cutting fluid is different in some aspects compared to the operation of the fluid cooling circuits of internal heat sources. While the fluid cooling circuits of internal heat sources mainly affect the machine structure, the process cooling circuit impacts the entire "machine-tool-workpiece" thermo-mechanical system. Moreover, there is an equally important, indirect impact on thermal error compensation models.

The effects of fluid cooling systems, including flood cooling techniques using cutting fluid, on MT thermal behaviour and thermal error compensation models are illustrated with the authors' recent research results. Chapter 2 focuses on the effects of fluid cooling systems 
on MT thermal error compensation models. In Chapter 3, measurements on a test bed (representing a vertical milling centre with a $\mathrm{C}$-shaped frame) and the measurement results of novel gradient regulation of the cooling unit are described, followed by a discussion about the influence of gradient regulation on thermal errors at the TCP. Finally, conclusions are drawn and suggestions concerning future research in this field are put forth.

\section{EFFECTS OF FLUID COOLING SYSTEMS ON THERMAL ERROR MODELS}

Pressure from MT manufacturers is logically applied to reduce the time required for machine testing and the overall time allocated to engineers to complete machines before shipment. This is also associated with the demand to minimize modelling time for thermal error compensation.

All of the following experiments have been performed on a gantry-type 5-axis milling centre with a rotary table (diameter $630 \mathrm{~mm}$ ). The MT was equipped with a number of internal temperature probes (RTD) primarily used for safety and diagnostic purposes which were installed in the MT control system by the MT manufacturer. The temperatures are recorded in $0.1^{\circ} \mathrm{C}$ and $0.5^{\circ} \mathrm{C}$ intervals. The tested machine is schematically shown in Fig. 5 alongside the approximate positions of the internal temperature probes used in the compensation models.

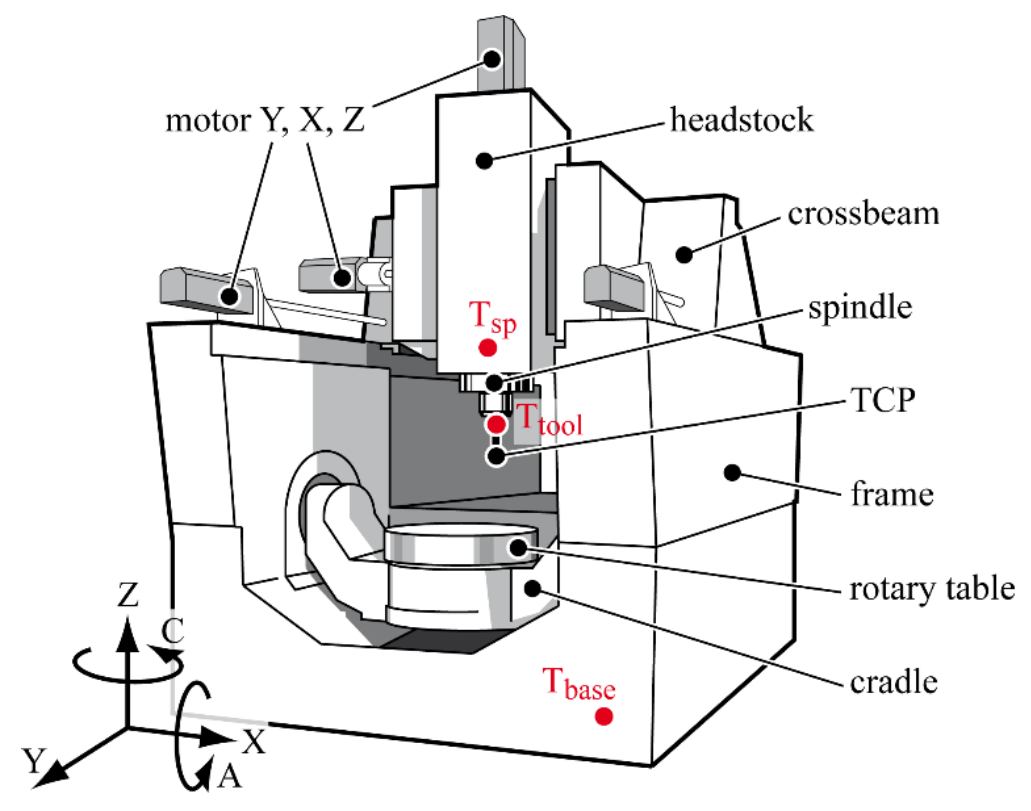

Fig. 5. General overview of the 5-axis milling machine with the approximate positions of internal temperature probes

The following research focused on testing the sensitivity of a thermal error compensation model based on TFs to uncalibrated changes in input parameters, in terms of both the difficulty of model modification and the time needed for additional testing on the milling centre. 
The frequency TF describes the link between the output (response) and the input (excitation) of a dynamic system in the frequency domain. If the system is linear, the TF is constant. TFs are commonly used in the analysis of analogue electronic circuits and mechanical systems. Application of TFs on thermo-mechanical systems has recently become an appealing phenomenon [18-22].

Thermo-mechanical TFs contain the nature of the heat transfer principles [18], thus the calibration of the empirical parameters is simpler and the model is also more reliable with untested inputs because the data is forced to conform to the same principles as the real process [23]. In addition, the results are obtained very quickly. These parameters make thermomechanical TFs suitable for real-time modelling and thermal and thermo-mechanical system diagnostics.

A discrete TF is used to describe the link between the excitation and the response equations (1) and (2):

$$
\begin{gathered}
y(t)=\varepsilon \cdot u(t)+e(t) \\
y(t)=\frac{a_{n} z^{-n}+\cdots+a_{1} z^{-1}+a_{0} z^{0}}{b_{m} z^{-m}+\cdots+b_{1} z^{-1}+b_{0} z^{0}} \cdot u(t) ;
\end{gathered}
$$

where $m>n$. The vector $u(t)$ in equations (1) and (2) is the TF input in the time domain, $y(t)$ is the output vector in the time domain, $\varepsilon$ represents the TF in the time domain, $e(t)$ is the disturbance value (further neglected), $a_{\mathrm{n}}$ are calibration coefficients of the TF input, $b_{\mathrm{m}}$ are calibration coefficients of the TF output, $n$ and $m$ are orders of the TF numerator and denominator respectively and $z$ is a complex number.

The difference form of a discrete TF (the generally suitable form for modern MT control systems using their programming languages) in the time domain is introduced in equation (3):

$$
\begin{array}{r}
y(k)=\frac{u(k-n) a_{n}+\cdots+u(k-1) a_{1}+u(k) a_{0}}{b_{0}} \\
-\left(\frac{y(k-m) b_{m}+\cdots+y(k-1) b_{1}}{b_{0}}\right)
\end{array}
$$

where $k$ represents the examined time period and $k-n(k-m)$ means the $n$-multiple ( $m$-multiple) delay in the sampling frequency of the measured input vector (simulated output vector). Linear parametric models of ARX (autoregressive with external input) or OE (output error) identifying structures are used to estimate TF coefficients. The stability of each TF and the relationship between the thermo-mechanical system input and output described by the TF are examined through linear time invariant (LTI) step response, see [24]. Excitations in TFs are temperatures measured close to heat sources and the responses stand for deformations in the examined directions. 
All model results are associated with approximation quality expressions. A global approximation quality of the simulated behaviour is expressed in equation (4). This value represents the percentage of the output variation reproduced by the model [24].

$$
f i t=\left(1-\frac{\left\|\delta_{m e a}-\delta_{\text {sim }}\right\|}{\left\|\delta_{m e a}-\bar{\delta}_{\text {sim }}\right\|}\right) \cdot 100 .
$$

The $\delta_{\text {mea }}$ value in equation (4) is the measured output (thermal deformation at the TCP), $\delta_{\text {sim }}$ is the simulated/predicted model output, and $\bar{\delta}_{\text {sim }}$ expresses the arithmetic mean of the measured output over time. The vector norm used in equation (4) is generally expressed as follows:

$$
\|\delta\|=\sqrt{\delta_{1}^{2}+\delta_{2}^{2}+\cdots \delta_{r}^{2}}
$$

where $\delta$ is a general vector of a length $r$.

An approximation quality focused on comparison of local extremes of both the simulated and measured behaviours is expressed in equation (6). This value represents the maximum thermal error measured after compensation model application at the TCP:

$$
\Delta p k=|\min (\delta)|+|\max (\delta)|
$$

where $\Delta p k$ is the abbreviation for a peak-to-peak evaluation method, i.e. the difference between the maximum positive and the maximum negative values of the examined behaviour.

\subsection{IMPACT OF COOLING SYSTEM MODIFICATION \\ ON SOFTWARE COMPENSATION EFFECTIVENESS}

Eddy current sensors firmly gripped in the measuring fixture were employed for noncontact sensing of the displacements between the TCP represented by a test mandrel (length $125 \mathrm{~mm}$, diameter $40 \mathrm{~mm}$ ) and the rotary table (regular workpiece position), per international standard ISO 230-3 [25], as shown in Fig. 6. Displacements were sensed in micrometre resolution.

The compensation TF model considers spindle rotation and the influence of timevarying ambient temperature in this case, except for the cutting process. Two temperature probes, $T_{\mathrm{sp}}$ and $T_{\text {base, }}$ are used as input into the thermal error model of the tested machine. The model predicts thermally induced displacements at the TCP in the most affected $Z$-direction. The model structure expressed by equation (7) is also introduced in [26]:

$$
\delta_{\mathrm{Z} \operatorname{sim}}=\underbrace{\left(\Delta T_{\mathrm{sp}}-\Delta T_{\text {base }}\right) \cdot \varepsilon_{1}}_{\text {spindle speed }}+\underbrace{\Delta T_{\text {base }} \cdot \varepsilon_{2}}_{\begin{array}{c}
\text { variation in } \\
\text { ambient } \\
\text { temperature }
\end{array}},
$$


where $\delta \mathrm{Z}_{\text {sim }}$ is the simulated/predicted model output, $\Delta T_{\mathrm{sp}}$ and $\Delta T_{\text {base }}$ express the relevant temperatures at the relative coordinates measured close to heat sources (see Fig. 5) and $\varepsilon_{1}$ and $\varepsilon_{2}$ represent TFs in a time domain describing the relationships between the relevant inputs and outputs (temperatures and deformational elements) of the thermo-mechanical system.

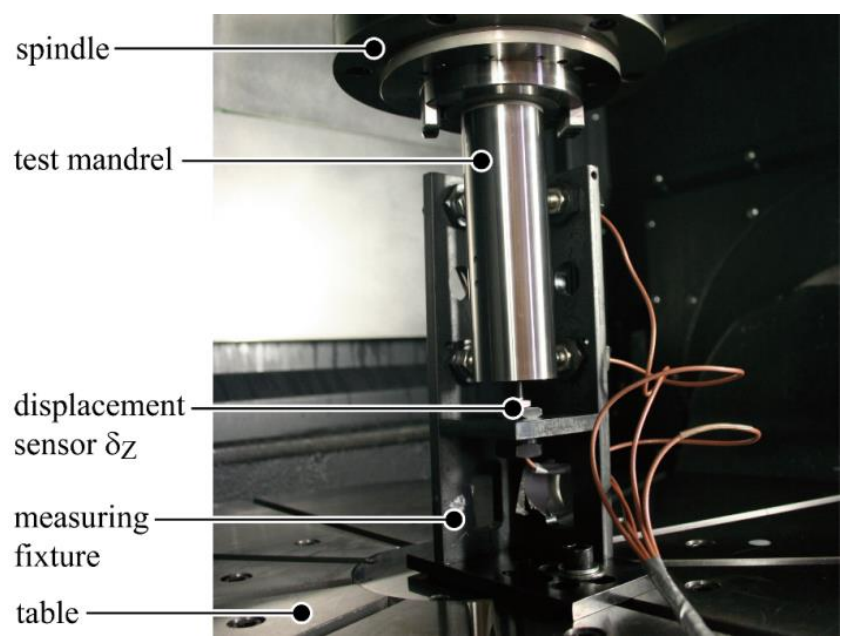

Fig. 6. Experimental setup in the MT workspace

The calibration coefficients of the two identified TFs for approximation of MT thermal errors in the Z-direction are shown in Table 1. The sets of identified TFs were selected according to the best fit value through the estimation process. The whole calibration process lasted up to 50 hours.

Table 1. Parameters of identified TFs

\begin{tabular}{|c|c|c|c|c|c|c|}
\hline TF & $a_{0}$ & $a_{1}$ & $a_{2}$ & $b_{0}$ & $b_{1}$ & $b_{2}$ \\
\hline$\varepsilon_{1}$ & -2.6573 & 5.1965 & -2.5392 & 1 & -1.9865 & 0.9865 \\
\hline$\varepsilon_{2}$ & -8.4280 & 8.4279 & 0 & 1 & -0.6913 & -0.3087 \\
\hline
\end{tabular}

All of the results and conclusions are associated with the following experiment conditions: the thermal error compensation model was valid for no-load or finishing conditions, the model was calibrated in one configuration of the MT axes (at the centre of the rotary table), and compensation was realized in the linear directions only. The 5-axis milling centre was equipped with a fluid-air-chiller (without a compressor unit) for the spindle during all calibration tests. The fluid-air-chiller works as an unregulated heat exchanger cooled by the ambient temperature with the help of a fan. Its main features are affordability and lower performance.

The compensation model sensitivity when the spindle cooling system was changed from the fluid-air-chiller to a commercial compressor cooler (HYDAC) is of further interest.

The more efficient and expensive compressor cooler regulates the coolant temperature according to the ambient temperature. All of the conducted verification tests are listed in Table 2. 
Table 2. Overview of verification tests

\begin{tabular}{|c|l|l|c|}
\hline No. & Spindle cooling principle & \multicolumn{1}{|c|}{ Spindle speed behaviour $[\mathrm{rpm}]$} & Time $[\mathrm{h}]$ \\
\hline 1 & Fluid-air-chiller (original) & $500,3000,6500,10000,0$ & 16 \\
\hline 2 & Compressor cooler & $500,3000,6500,10000,0$ & 16 \\
\hline 3 & Compressor cooler & $500,3000,6500,10000,0,500,3000,6500,10000,0,6000,0$ & 62 \\
\hline
\end{tabular}

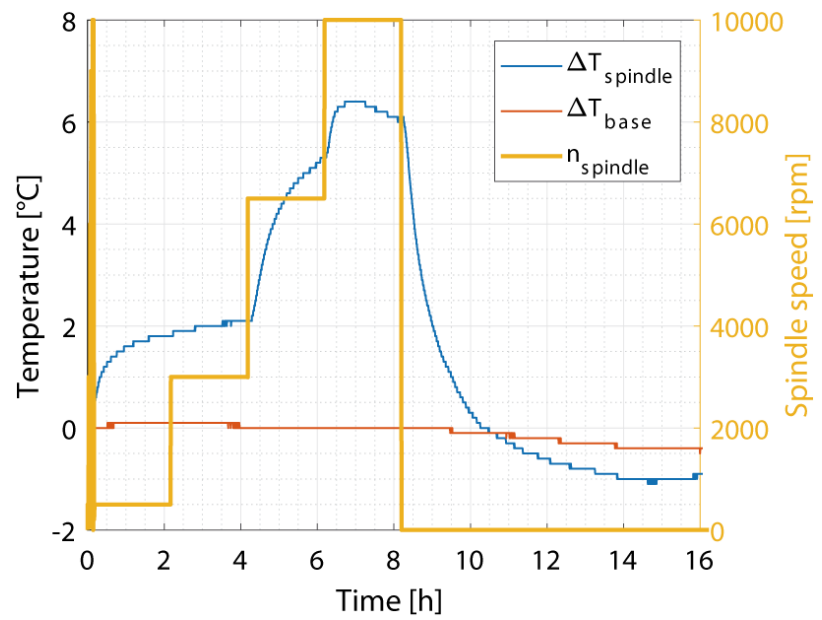

Fig. 7. Inputs into the thermo-mechanical system during the first verification test with the original spindle cooling principle

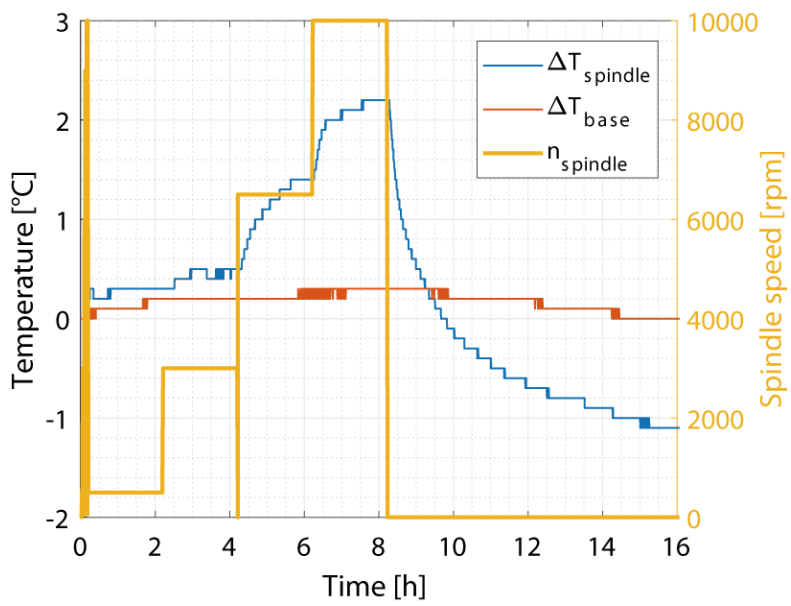

Fig. 9. Inputs into the thermo-mechanical system during the second verification test with the new spindle cooling principle

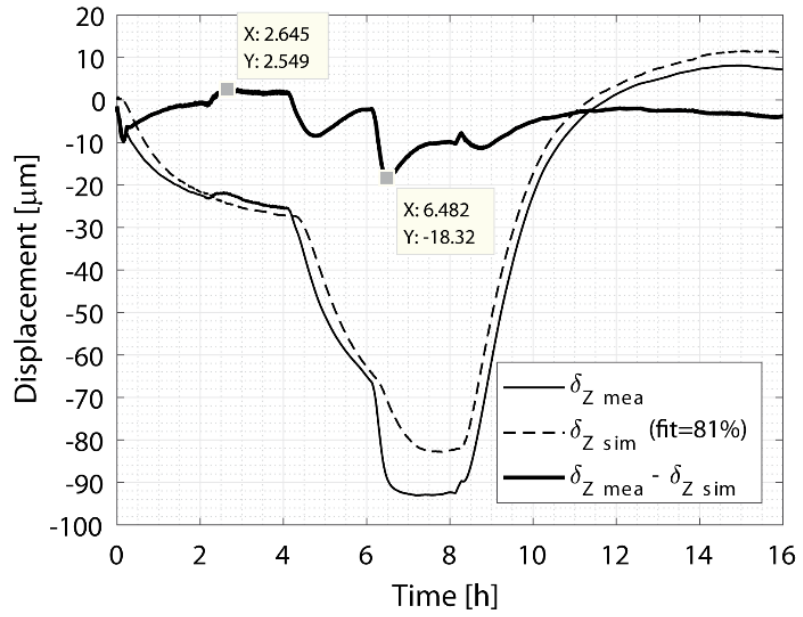

Fig. 8. Measured and simulated outputs from the thermo-mechanical system during the first verification test with the original spindle cooling principle

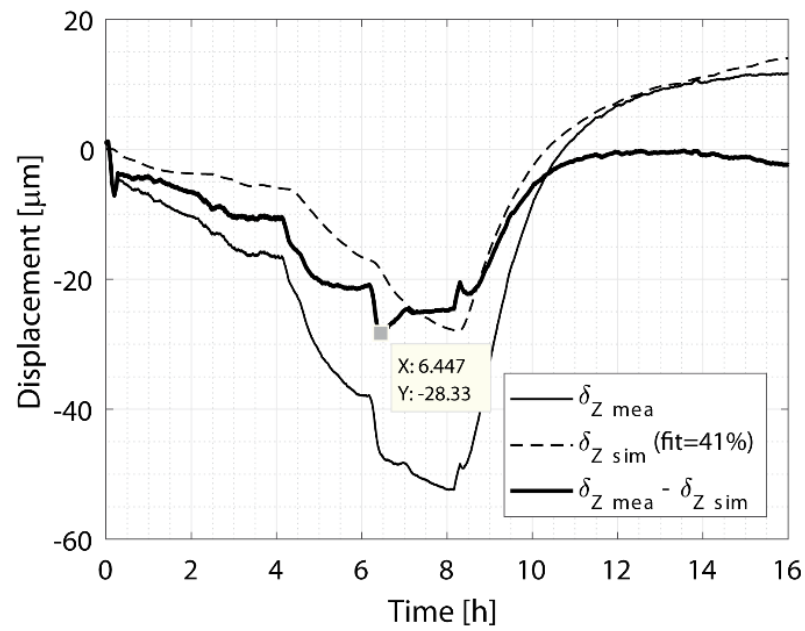

Fig. 10. Measured and simulated outputs from the thermo-mechanical system during the second verification test with the new spindle cooling principle

The first verification test consisted of spindle speed variation with the original fluid-airchiller. The setup of the spindle speed variation and model input temperature behaviours is shown in Fig. 7. 
The measured ( $\left.\delta_{\mathrm{Z} \text { mea }}\right)$, simulated [according to $\left.(7)\left(\delta_{\mathrm{Z} \text { sim }}\right)\right]$ and residual $\left(\delta_{\mathrm{Z} \text { mea }}-\delta_{\mathrm{Z} \text { sim }}\right)$ deformations during the first verification test are depicted in Fig. 8. The approximation quality of the compensation model from equation (7) is $81 \%$ expressed by the fit value, and $21 \mu \mathrm{m}$ out of the original $102 \mu \mathrm{m}$ from the $\Delta p k$ point of view.

The second verification test consisted of similar spindle speed variation to the first verification test. The difference between the two experiments was that the spindle cooling system was changed from the original fluid-air-chiller to the more efficient compressor cooler.

The setup of the spindle speed variation and model input temperature behaviours is shown in Fig. 9. The spindle bearing temperature decreased two-fold through the application of the new spindle cooling system. The measured, simulated and residual deformations during the second verification test are depicted in Fig. 10. The deformations in the Z-direction decreased 1.6-fold compared to the previous test (see Fig. 8) with the fluid-air-chiller and the approximation quality of the compensation model from equation (7) is $41 \%$ expressed by the fit value. The maximum deformations expressed by the $\Delta p k$ value were reduced from the original $67 \mu \mathrm{m}$ to $28 \mu \mathrm{m}$.

There are several approaches to compensation model modification, which differ in the degree of modelling difficulty and the time required for additional calibration experiments. The developed compensation model based on TFs has an open structure which enables easy modification of different thermal source impacts because there are separate solutions for each of the participating deformational elements on the overall thermal error [27]. Thus, the modification of the TF model due to the change in the cooling unit can be realized via a spindle speed sub-model gain, shown in equation (7), whereas the ambient temperature impact sub-model can remain unchanged. This concept assumes similar time constants of the thermo-mechanical phenomenon. Considering these assumptions, equation (7) may be modified:

$$
\delta_{Z \operatorname{sim}}=\left(\Delta T_{s p}-\Delta T_{\text {base }}\right) \cdot \varepsilon_{1} \cdot g+\Delta T_{\text {base }} \cdot \varepsilon_{2}
$$

where $g=1.7$ is the experimentally obtained gain factor of the spindle speed sub-model. The result of modified TF compensation model application on the second verification test is depicted in Fig. 11. The modification increased the global approximation quality (expressed by the fit values according to (4)) of the original model by $40 \%$. The maximum residual deformations dropped two-fold to $15 \mu \mathrm{m}$.

The third test was conducted to verify the correctness of the model modification assumptions expressed by equation (8). The verification test consisted of three spindle speed spectra with compressor cooler activity divided according to the MT cooling phases. The duration of the experiment was 62 hours. The setup of the spindle speed variations and model input temperature behaviours is shown in Fig. 12. The measured, simulated and residual deformations during the third verification test are depicted in Fig. 13. The global approximation quality expressed by the fit value of the compensation model from equation (8) remains at a satisfactory level, i.e. 75\%. A reduction from the original $80 \mu \mathrm{m}$ to $29 \mu \mathrm{m}$ was achieved from the local approximation quality point of view ( $\Delta p k$, see equation (6)). 


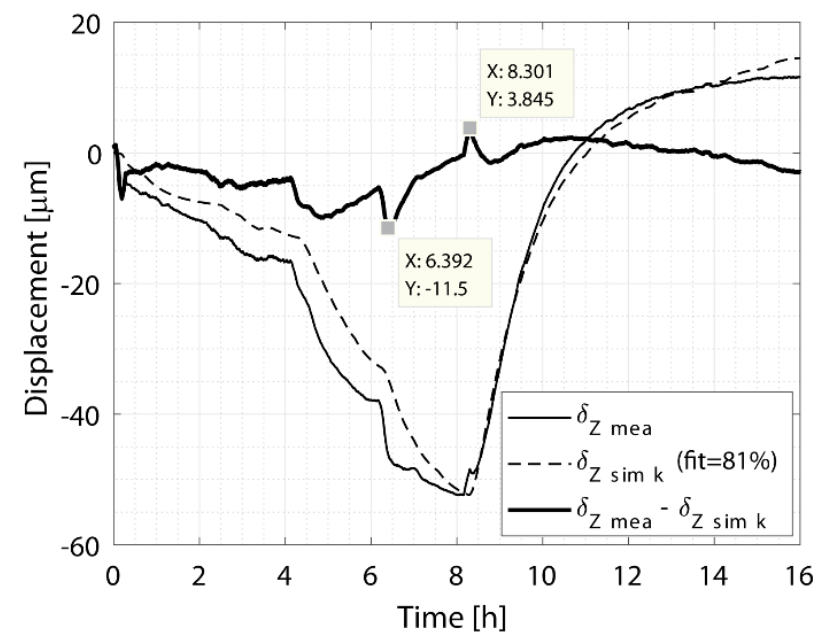

Fig. 11. Measured and corrected model simulated outputs from the thermo-mechanical system during the second verification test with the new spindle cooling principle

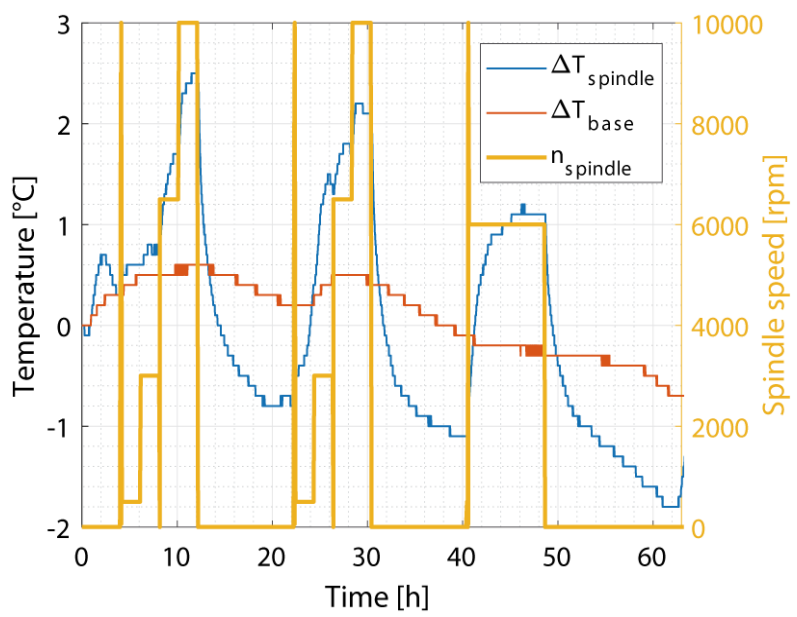

Fig. 12. Inputs into the thermo-mechanical system during the third verification test with the new spindle cooling principle

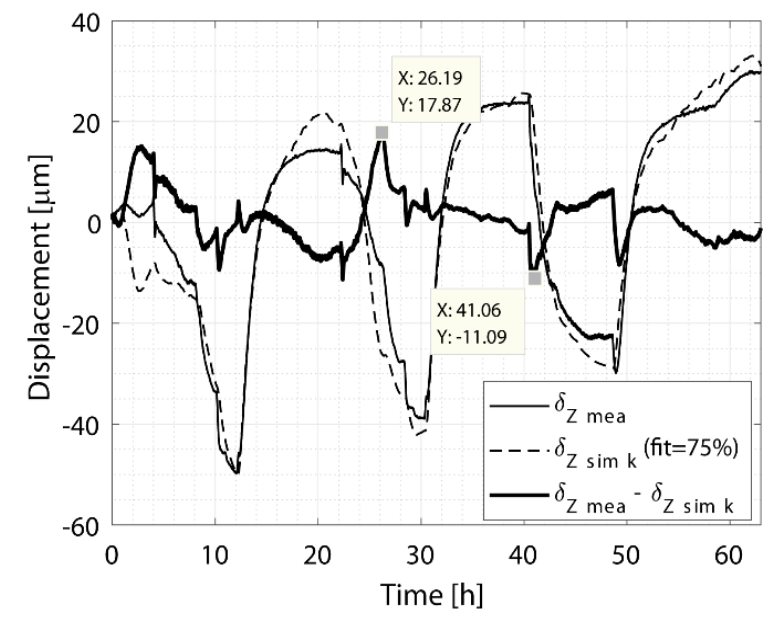

Fig. 13. Measured and corrected model simulated outputs from the thermo-mechanical system during the third verification test with the new spindle cooling principle

The accuracy could be further improved by performing a new calibration measurement of the spindle speed impact under the action of the new cooling system or by resolving spindle rotation and cooling system impacts on MT thermo-mechanical behaviour separately with subsequent superposition, see [28]. The first option would entail additional experiments and more time spent on the machine and the second option would also require finding a new suitable input into the sub-model solution for the cooling system impact on MT thermal error.

\subsection{INFLUENCE OF CUTTING FLUID ON MACHINE TOOL THERMAL ERRORS}

The TF compensation model from equation (7) was enriched with a sub-model to resolve the impact of the cutting process on MT thermal behaviour. Including the cutting process 
impact in the existing TF model is simple because the model structure is open to description of additional thermal sources (see Chapter 2.2). The extended model is introduced in (9):

$$
\delta_{Z \operatorname{sim}}=\left(\Delta T_{\mathrm{sp}}-\Delta T_{\text {base }}\right) \cdot \varepsilon_{1}+\Delta T_{\text {base }} \cdot \varepsilon_{2}+\underbrace{\Delta T_{\text {tool }} \cdot \varepsilon_{3}}_{\begin{array}{c}
\text { tool elongation } \\
\text { due to a cutting } \\
\text { process }
\end{array}},
$$

where the term $\Delta T_{\text {tool }}$ expresses the tool temperature at relative coordinates measured close to heat sources (cutting process) and $\varepsilon_{3}$ represents the TF in a time domain describing the relationships between the relevant inputs and outputs (the tool temperature and tool elongation due to the cutting process) of the thermo-mechanical system.

The model was verified for different technological parameters (finishing, semifinishing and rough machining) and cutting tools (differing tool diameter and number of inserts). The model calibration, architecture and verification are described in [1] in detail.

The calibration coefficients of the identified additional TF for approximation of MT thermal errors caused by the cutting process in the Z-direction are shown in Table 3.

Table 3. Parameters of the identified TF for cutting process impact, see [1]

\begin{tabular}{|c|c|c|c|c|c|c|}
\hline TF & $a_{0}$ & $a_{1}$ & $a_{2}$ & $b_{0}$ & $b_{1}$ & $b_{2}$ \\
\hline$\varepsilon_{3}$ & -0.4099 & 0.1057 & 0.2872 & 1 & -0.2835 & -0.7063 \\
\hline
\end{tabular}

A cylindrical-shaped workpiece of medium-carbon steel material 1.0503 and a cutting tool with a $63 \mathrm{~mm}$ diameter (five inserts) were used in further verification tests. The cutting process and thermal error measurement methodologies (duration of loading and measuring phases, tool temperature and deformation measurement, tool path, etc.) are described in [1] in detail. An overview of the MT workspace containing the experimental setup along with the details of the measurement position is shown in Fig. 14.
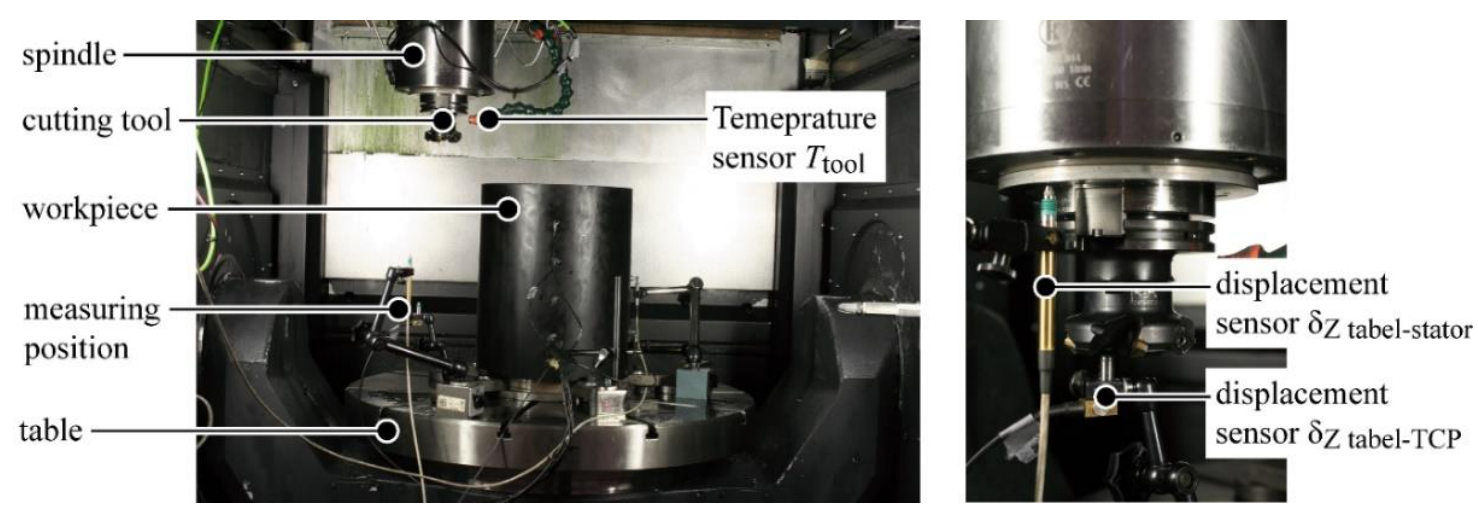

Fig. 14. Experimental setup in the MT workspace (left) and a detail of the measurement position (right)

All of the results and conclusions are associated with the following experiment conditions: the model (including all sub-models) was calibrated in one configuration of the MT axes, the tool elongation sub-model was identified for dry cutting conditions (no cutting 
fluid), the model was built-up except for workpiece deformations and the impact of removed material and compensation was only realized in the linear direction of the $Z$ axis.

The compensation model sensitivity to a change in the technological process due to the presence of cutting fluid (as shown in Fig. 15Fig.) is also of interest. The parameters of cutting fluid application (volume, nuzzle directions, etc.) were set according to the MT producer's standards.

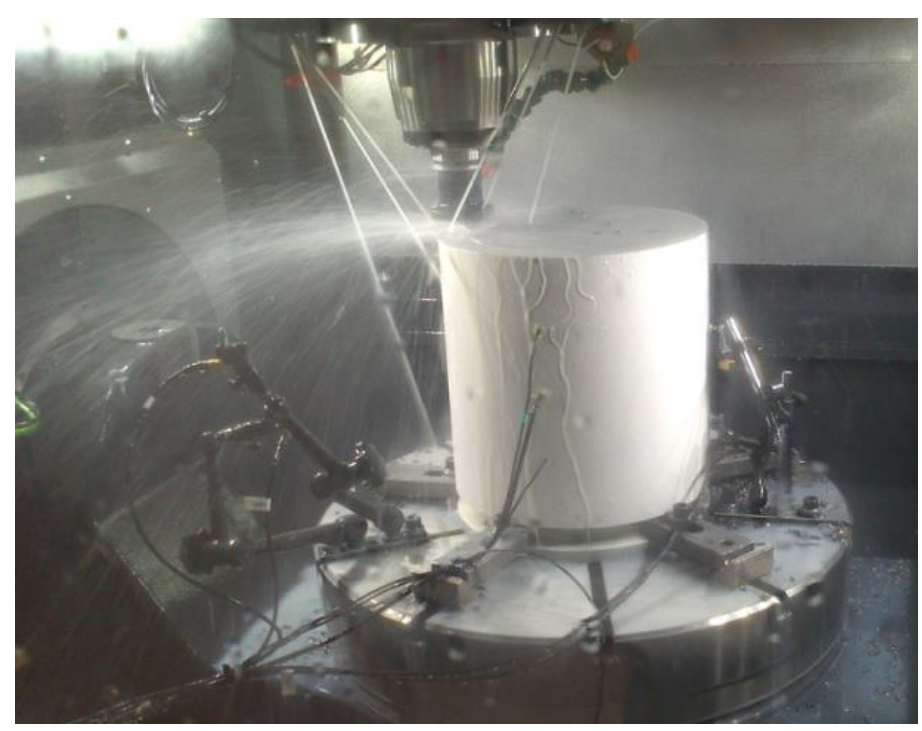

Fig. 15. Cutting fluid in machining verification tests

All of the verification tests along with the cutting parameters are listed in Table 4 . The verification tests can be divided into two groups with the same cutting parameters, differing only in the presence or absence of cutting fluid: semi-finishing and rough machining.

Table 4. Overview of verification tests and cutting parameters

\begin{tabular}{|l|l|l|c|c|c|c|c|}
\hline No. & Cutting fluid & Technological process & $a_{\mathrm{p}}[\mathrm{mm}]$ & $v_{\mathrm{f}}[\mathrm{mm}]$ & $n_{\text {sp }}[\mathrm{rpm}]$ & $P[\mathrm{~kW}]$ & Time $[\mathrm{h}]$ \\
\hline 1 & No & Semi-finishing & 1.5 & 758 & 758 & 0.3 & 3.5 \\
\hline 2 & Yes & Semi-finishing & 1.5 & 758 & 758 & 0.3 & 6.5 \\
\hline 3 & No & Rough machining & 3 & 668 & 477 & 2.5 & 12 \\
\hline 4 & Yes & Rough machining & 3 & 668 & 477 & 2.5 & 37 \\
\hline
\end{tabular}

The first verification test consisted of dry machining with semi-finishing cutting parameters. The experiment setup of the spindle speed and model input temperature

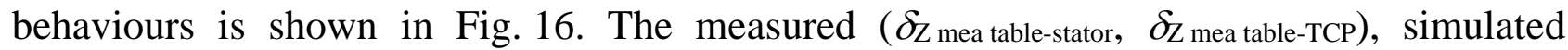

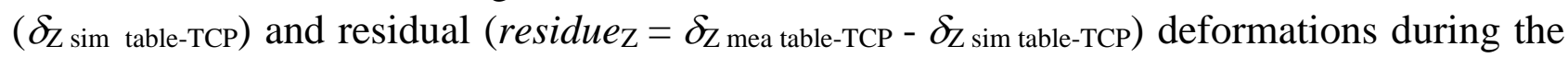
first verification test are depicted in Fig. 17. The approximation quality of the compensation model from equation (9) is $73 \%$ expressed by the global indicator fit. The cooling phase was not recorded. 


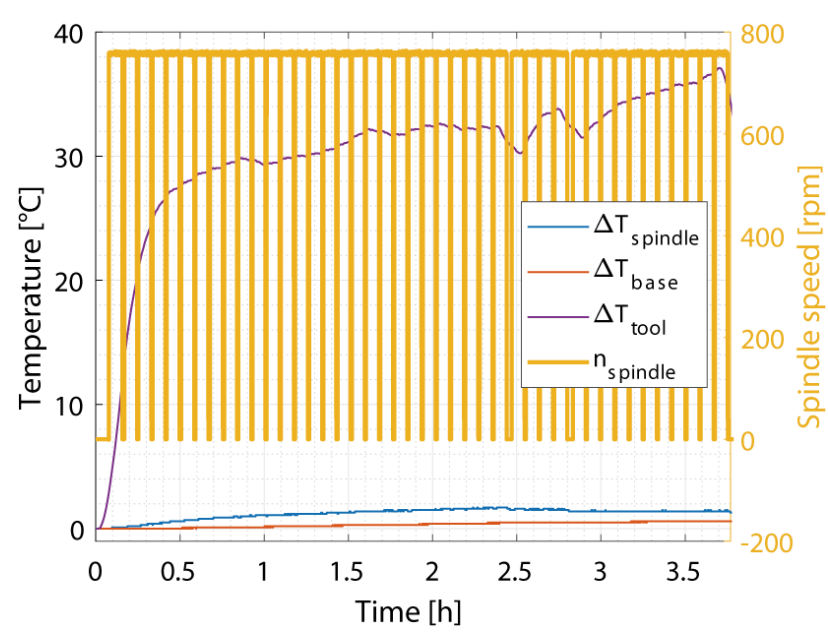

Fig. 16. Inputs into the thermo-mechanical system during the first verification test for dry machining and semifinishing conditions

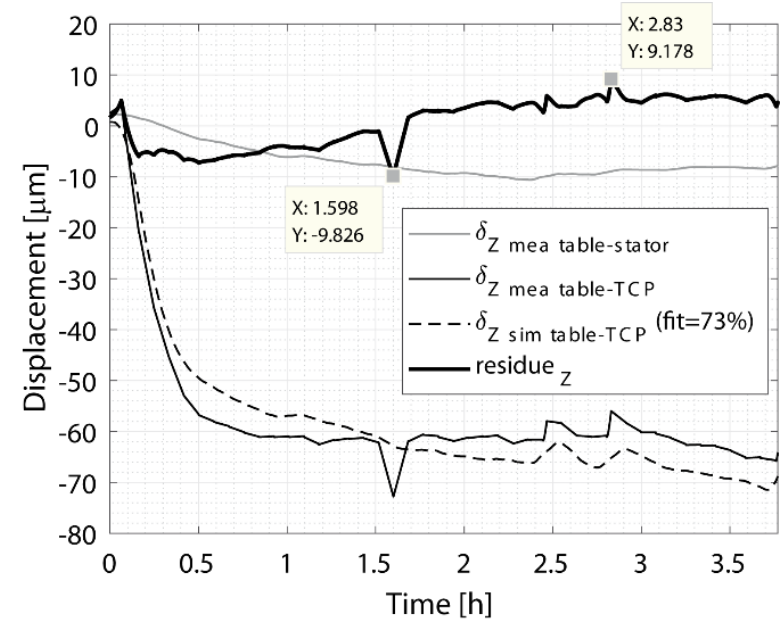

Fig. 17. Measured and simulated outputs from the thermo-mechanical system during the first verification test for dry machining and semi-finishing conditions

The second verification test consisted of a similar cutting parameter setup to the previous test, apart from cutting fluid presence. The setup of the spindle speed and model input temperature behaviours is shown in Fig. 18. The relative tool temperature decreased six-fold through the application of cutting fluid during the machining process. The measured, simulated and residual deformations during the second verification test are depicted in Fig. 19. Uncompensated deformations in the Z-direction, measured at the TCP, decreased 2.8 -fold compared to the previous test for dry machining. The approximation quality of the compensation model from equation (9) is $40 \%$ expressed by the fit value. The effectivity of the compensation model decreased through cutting fluid application, but resulted in a thermal error reduction of 4.75 -fold compared to the uncompensated state under dry machining. A good approximation of the cooling phase is observable in Fig. 19.

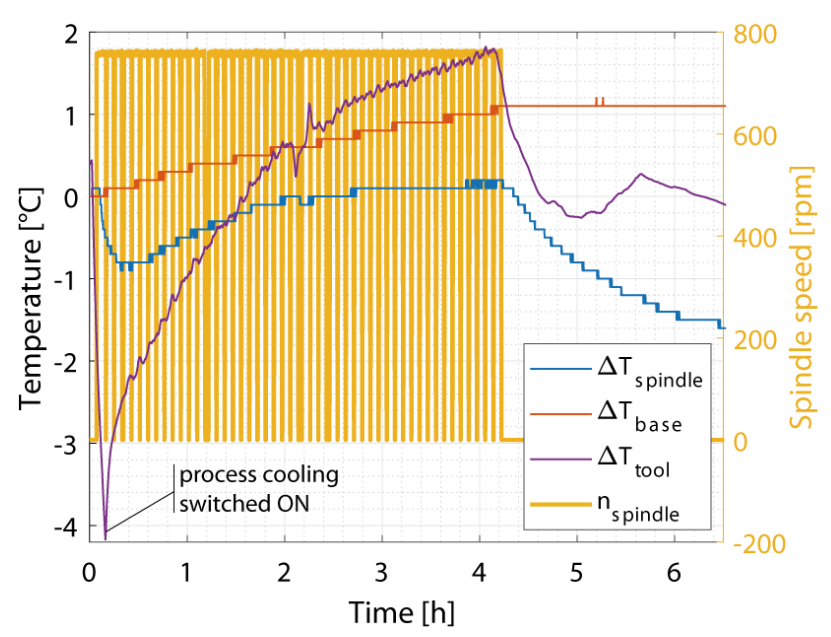

Fig. 18. Inputs into the thermo-mechanical system during the second verification test under wet machining and semi-finishing conditions

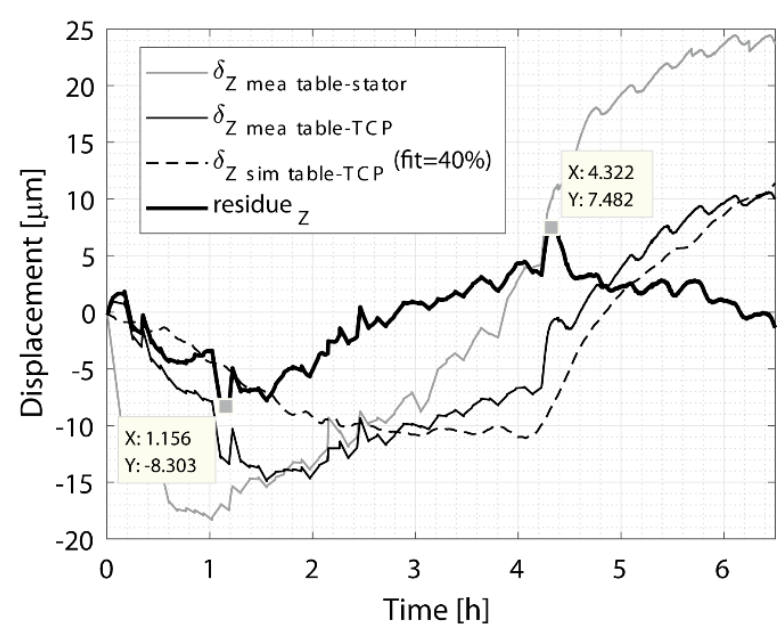

Fig. 19. Measured and simulated outputs from the thermo-mechanical system during the second verification test under wet machining and semifinishing conditions 
The results from testing under semi-finishing conditions are summarised in Table 5.

Table 5. Results of verification tests under semi-finishing cutting conditions

\begin{tabular}{|c|l|c|}
\hline No. & Experiment setup & $\Delta p k[\mu \mathrm{m}]$ \\
\hline \multirow{2}{*}{1} & Dry machining & 76 \\
\cline { 2 - 3 } & Dry machining with active model & 19 \\
\hline \multirow{2}{*}{2} & Wet machining & 27 \\
\cline { 2 - 3 } & Wet machining with active model & 16 \\
\hline
\end{tabular}

The third verification test consisted of rough machining without cutting fluid application. The experimental setup of the spindle speed and model input temperature behaviours is shown in Fig. 20. The measured, simulated and residual deformations are depicted in Fig. 21. The approximation quality of the compensation model from equation (9) is $77 \%$ expressed by the fit value. Two tool changes due to insert wear were necessary during the loading phase of the experiment.

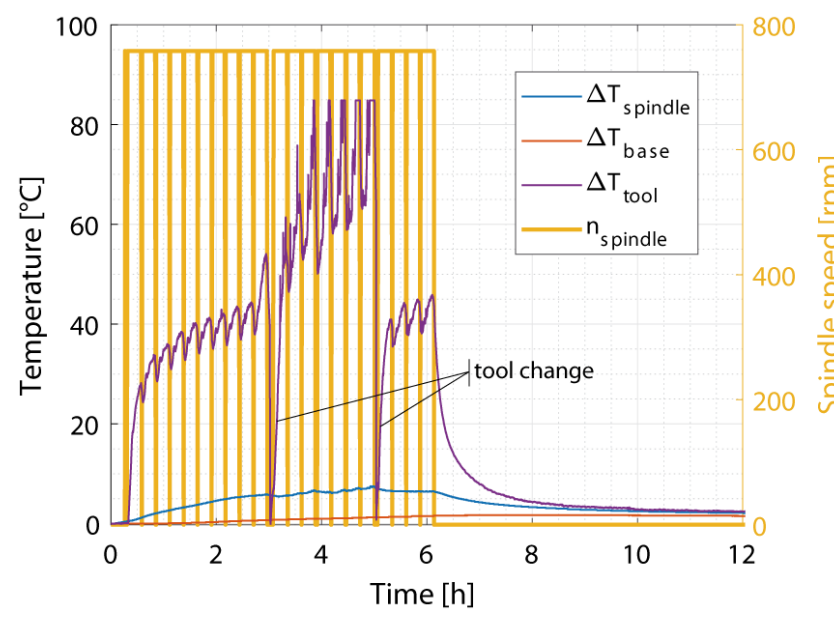

Fig. 20. Inputs into the thermo-mechanical system during the third verification test for dry rough machining

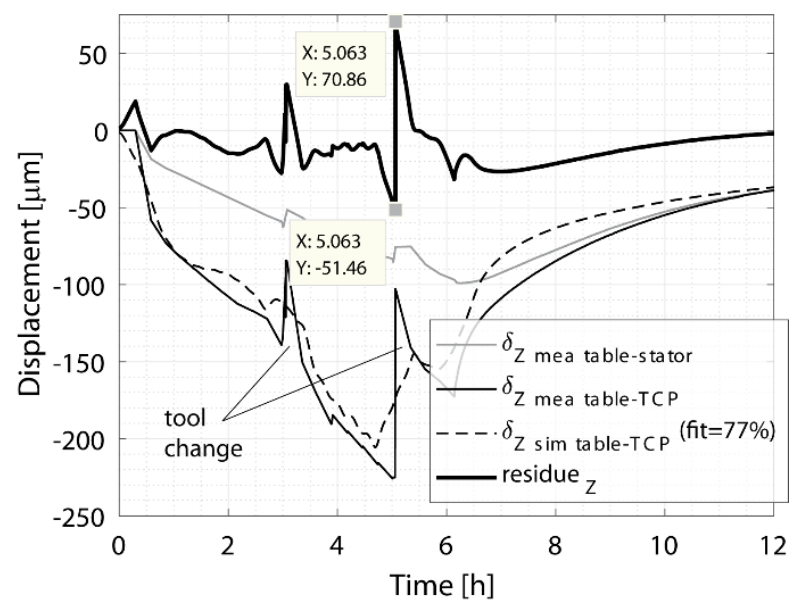

Fig. 21. Measured and simulated outputs from the thermo-mechanical system during the third verification test for dry rough machining

The fourth verification test consisted of a similar cutting parameter setup to the previous test, apart from cutting fluid presence. The setup of the spindle speed and model input temperature behaviours is shown in Fig. 22.

The relative tool temperature decreased 14-fold through the application of cutting fluid during the machining process. The measured, simulated and residual deformations during the fourth verification test are depicted in Fig. 23. Uncompensated deformations in the Z-direction decreased eight-fold compared to the previous test for dry machining. The approximation quality of the compensation model is $34 \%$ expressed by the fit value. Cutting fluid application decreased the effectivity of the compensation model, but resulted in 
a thermal error reduction of 15-fold compared to the uncompensated state under dry machining conditions. The stability of the compensation model during the long-term cooling phase (over 30 hours) is observable in Fig. 23. The test results for rough machining are summarized in Table 6.

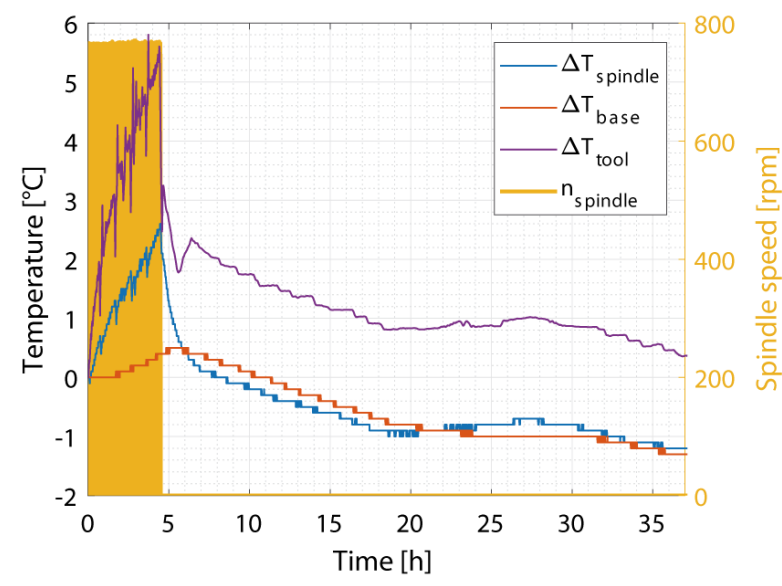

Fig. 22. Inputs into the thermo-mechanical system during the fourth verification test for wet rough machining

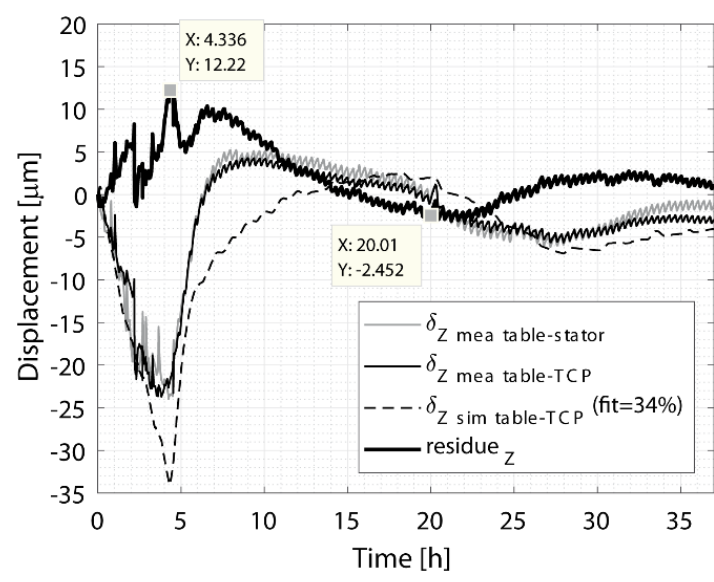

Fig. 23. Measured and simulated outputs from the thermo-mechanical system during the fourth verification test for wet rough machining

Table 6. Results of verification tests for rough machining

\begin{tabular}{|c|l|c|}
\hline No. & Experiment setup & $\Delta p k[\mu \mathrm{m}]$ \\
\hline \multirow{2}{*}{3} & Dry machining & 230 \\
\cline { 2 - 3 } & Dry machining with active model & 122 \\
\hline \multirow{2}{*}{4} & Wet machining & 28 \\
\cline { 2 - 3 } & Wet machining with active model & 15 \\
\hline
\end{tabular}

Note that the relatively high $\Delta p k$ value $(122 \mu \mathrm{m})$ of the compensated state achieved during the third test occurred during a period of tool change when there was considerable measurement uncertainty.

Modelling based on experimental data of cutting fluid impact on MT thermal errors is complicated. However, a TF compensation model calibrated for dry machining conditions with appropriate temperature inputs can achieve a significant reduction in thermal errors even with the use of cutting fluid.

\section{ENHANCEMENT OF MACHINE TOOL ACCURACY THROUGH COOLING SYSTEM CONTROL}

A common approach to controlling the cooling unit is to use the heat exchanger (HEX) input, output or both to control the cooling liquid temperature [29]. As a controllable element, it is possible to use the three-way mixing valve to mix the HEX output liquid with the cool liquid from the reservoir or control the flow through the HEX. Both methods lead to the same 
result: constant HEX output. This form of cooling regulation is herein denoted as fixed regulation. In the case of measuring structure temperature, derivation of the regulation process variable instead of the liquid temperature is denoted as gradient regulation. To determine the impact of both methods the test bed was assembled, see Fig. 24.

The test bed consists of a C-shaped frame [30], which was equipped with the HEX and an electric heater. The $\mathrm{C}$-frame is similar to a 3-axis vertical milling machine, therefore the deformation at the TCP was determined as the overall output of the thermo-mechanical system. Deformations may be measured in three axes $\left(\delta_{X}, \delta_{Y}, \delta_{Z}\right)$.

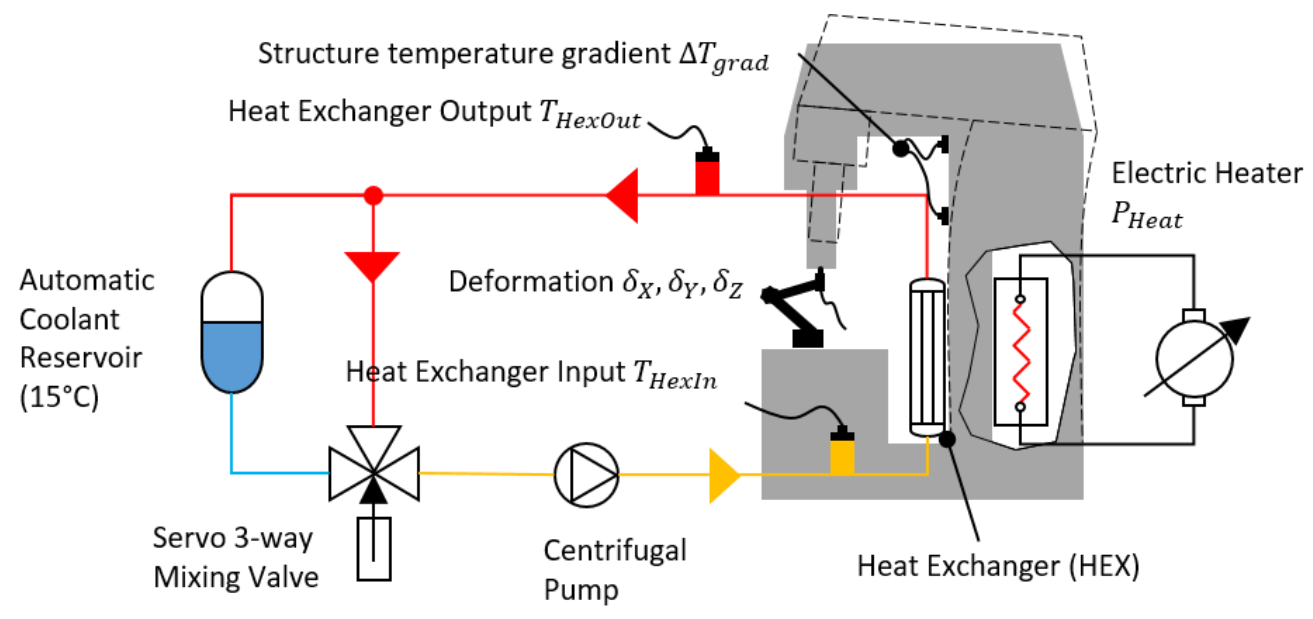

Fig. 24. Scheme of the experimental rig

The cooling unit consists of an automatic coolant reservoir, which maintains the refrigerator to keep the coolant liquid at a temperature of $15^{\circ} \mathrm{C}$. The test bed was also equipped with a 3-way mixing valve, which was able to receive analogue voltage signals as the control input. It was also possible to control the centrifugal pump with a fixed impeller speed. However, this feature was used to correct the overcooled state. This means that when the regulator overshoots the required temperature (i.e., overcools the structure), the three-way valve is set to recirculation and the pump to the highest rotation speed (rpm). This creates the state machine, which consists of two stages: the liquid temperature control state and the compensation process variable overshoot state.

Before explaining the difference in the regulators, it is appropriate to introduce the overall thermo-mechanical behaviour of the entire setup. As shown in Fig. 25, there is the electric heater performance spectrum and liquid temperatures at the input and the output of the HEX, respectively.

It is obvious that the heat coming from the heater is reflected only in the output line. This behaviour is caused by expanded liquid leakage and is affected by the very close location of the $T_{\text {HexOut }}$ temperature sensor. As mentioned earlier, this experiment was meant to be without cooling, and thus the flow rate was set to $01 / \mathrm{min}$. In Fig. 26, there is a record of deformation at the TCP in three axes. It is evident that the heating procedure in the $Z$-direction has the greatest impact. For this performance spectra, the maximum deformation 
value was $180 \mu \mathrm{m}$ and the state was still not steady. This could give the impression that the cooling contributes positively in both control ways.

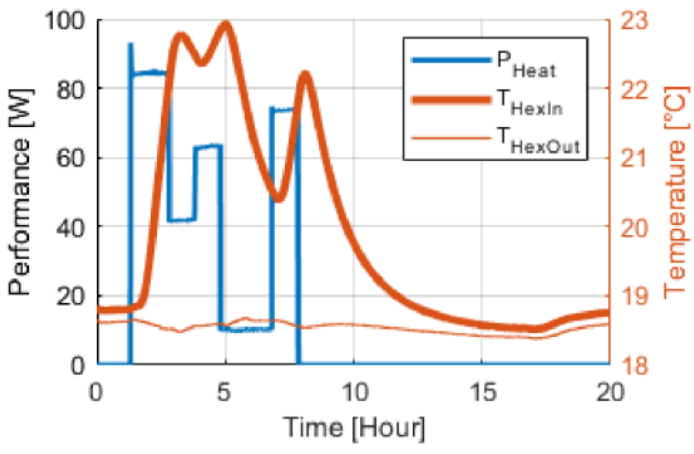

Fig. 25. Thermo-mechanical system input without cooling identification tests

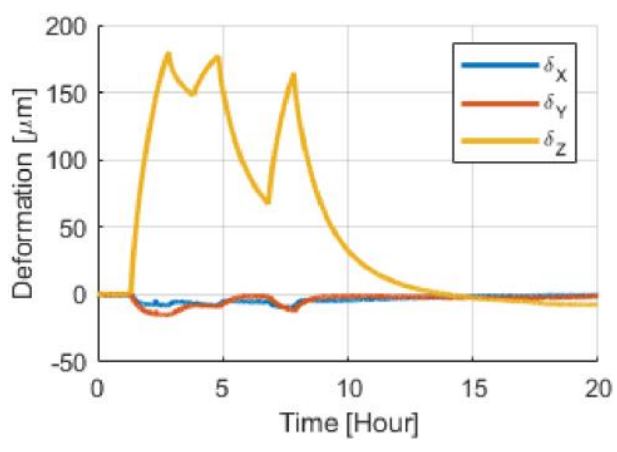

Fig. 26. Thermo-mechanical system output without cooling identification tests

As can be seen in Fig. 27, the regulator for both methods was very simple - a PID regulator with different feedback and P, I, D parameters for each method. It was crucial to initialize the experiment. This consists of determining the required setpoint values with respect to the ambient temperature and natural thermal gradient (measured in the steady state, given by the temperature difference between the floor and ceiling). During the initialization phase, the reference values were set as $T_{r e q}$ and $\Delta T_{\text {req }}$, which were derived from the ambient temperature and the natural gradient.

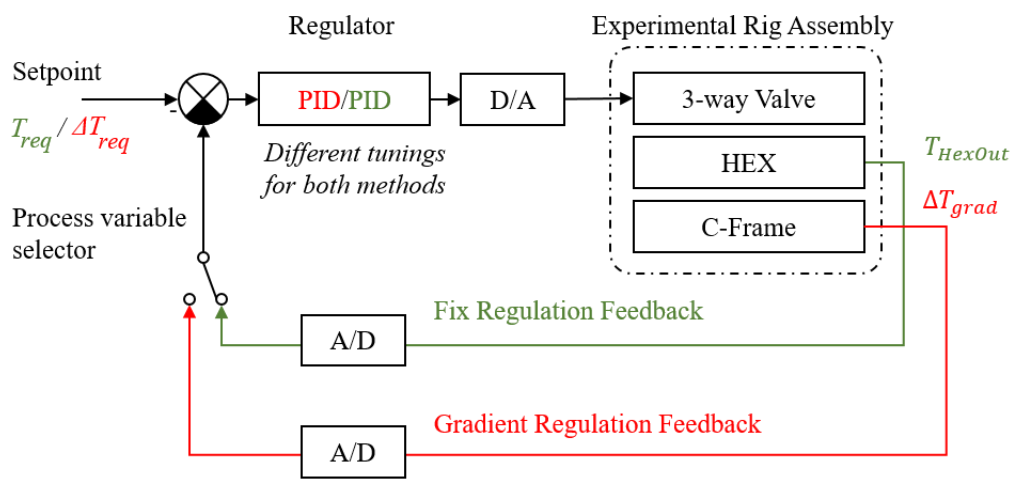

Fig. 27. Regulator with feedback selector

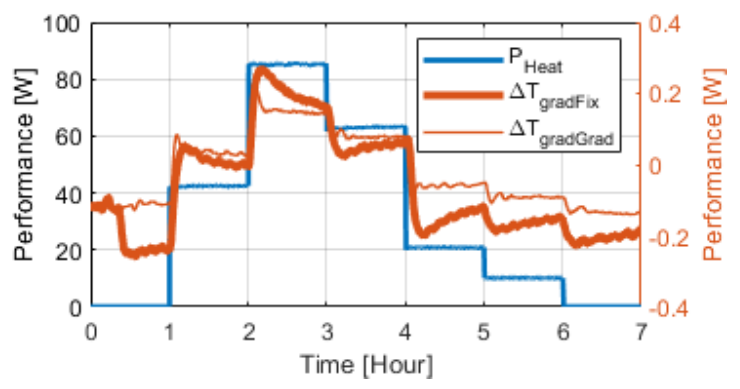

Fig. 28. Thermal gradient comparison for each regulation method 
The thermal gradient of the C-frame structure for both methods may be compared, see Fig. 28. In the case of gradient control, the regulator compensated the temperature gradient overshoot (observable in the $\Delta T_{\text {gradFix }}$ line). Furthermore, it will be shown that this had a fundamental effect on the reduction of deformation.

With the fixed regulation approach, one constant heat source is added, which weakens the effect of the electric heater. The fact that it is constant may be seen in Fig. 29. The saw shape signal of both temperatures was caused by a backlash in the mechanism of the 3-way valve. Nevertheless, it was possible to keep the heat flow though the HEX within reasonable limits. In Fig. 30, it is possible to see that the negative influence of the electric heater on thermal behaviour was significantly decreased. The deformation of the most affected $Z$-direction decreased dramatically compared to the non-cooled state (see Fig. 26).

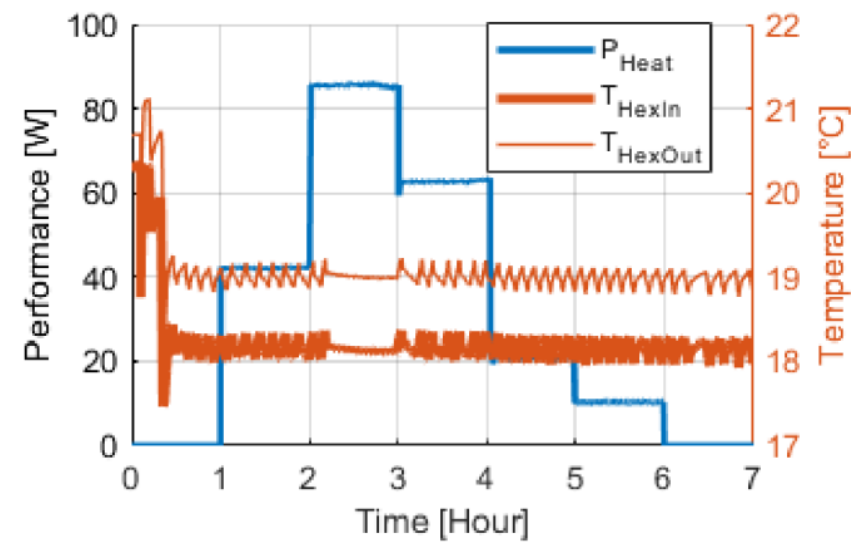

Fig. 29. Thermo-mechanical system input during fixed regulation method experiments

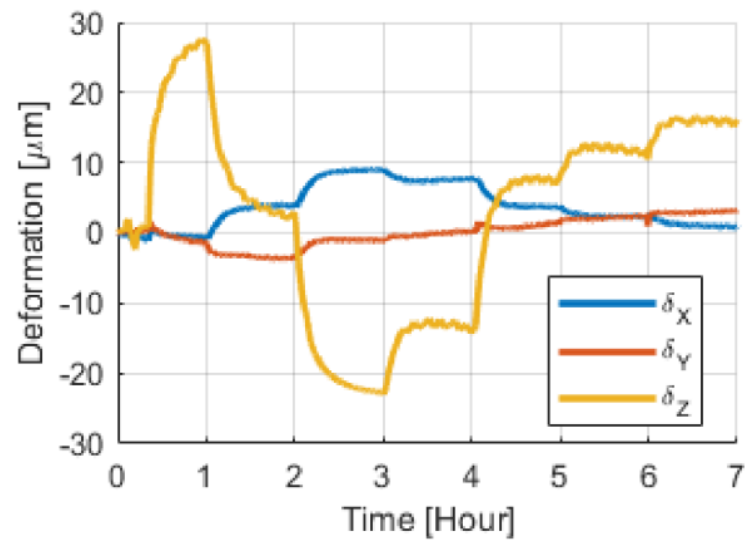

Fig. 30. Thermo-mechanical system output during fixed regulation method experiments

In the case of gradient regulation, the reaction of the system followed electric heater performance. As may be seen in Fig. 31, the shape of the input and output of the HEX is reciprocal to heater performance. Thus, the resultant thermally induced displacement at the TCP was decreased even further (see Fig. 32).

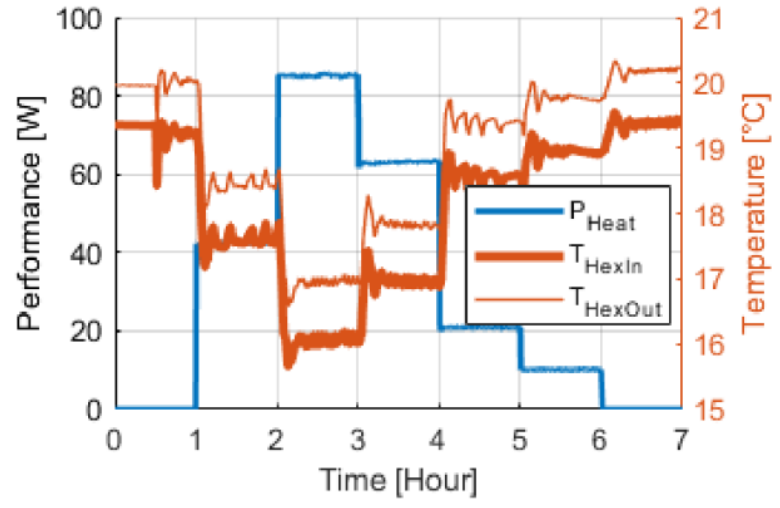

Fig. 31. Thermo-mechanical system input during gradient regulation method experiments

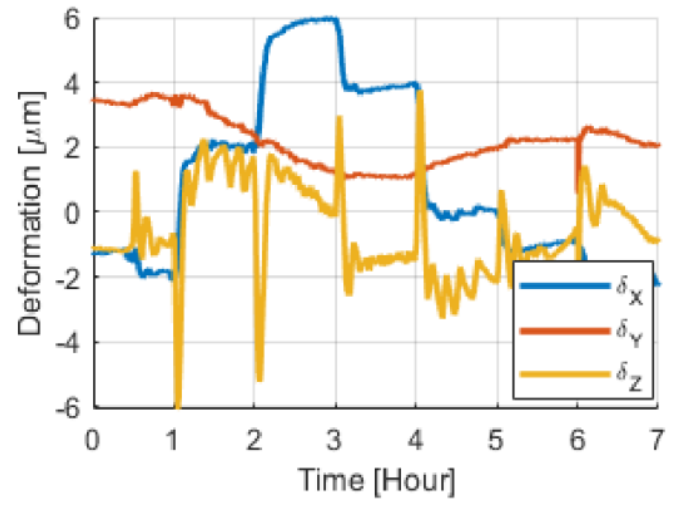

Fig. 32. Thermo-mechanical system output during gradient regulation method experiments 
The X-direction had the largest contribution of deformation after application of gradient regulation. The main deformation in $Z$-direction is suppressed below the other coordinates $X$ and $Y$ and in comparison to the non-cooled state the gradient regulation method decreases thermal error by two orders of magnitude. The residual deformation of the $X$ and $Y$-direction may be compensated by identifying TFs of this thermal behaviour (the modelling approach was presented in [30]). Such a model could act as a compensation algorithm which could prepare correction values for servo drives. The experimental rig was not equipped with any actuator, thus the calculated values would only give a theoretical presentation of the method.

\section{CONCLUSION}

The main objective of this paper is to provide an overview of the effects of internal heat source cooling systems and cutting fluids on MT thermal errors and strategies for their mitigation, especially the impact on thermal error compensation models. The effects of fluid cooling systems on MT thermal behaviour and thermal error compensation models are illustrated with the author's recent research results.

Firstly, different types of tests were carried out on a gantry-type 5-axis milling centre with a rotary table and symmetrical structure to investigate the sensitivity of a thermal error compensation model based on TFs to modification of the fluid cooling systems and cutting fluid presence. It was demonstrated that a modelling approach using TFs has the potential to deal with these issues. It is primarily due to the open structure of the developed TF compensation model based on the linearization of MT thermal issues (separate solutions for each of the participating deformational elements caused by different heat sources on overall thermal errors). This enables easy integration of different heat source (or heat sink) impacts, and furthermore transparent and fast modification of the sub-models addressing particular influences (e.g. modification of the cooling system, cutting fluid presence, etc.).

In case of modification of the cooling system, the simple modification via a spindle speed sub-model gain factor increased the global approximation quality expressed by the fit value according to (4) of the original model by $40 \%$. An additional example is modification of the technological process through the presence of cutting fluid (dry cutting or wet cutting). Despite the fact that the modelling of cutting fluid impact on MT thermal errors is very complex and complicated, the TF compensation model calibrated for dry machining conditions with appropriate temperature inputs could achieve a significant reduction in thermal errors even with the use of cutting fluid. Thus, it was shown that the open structure of the thermal error compensation models based on TFs is a very efficient time-saver because it allows significant reduction of time spent on the machine due to the realization of additional experiments to build a new compensation model as well as the time savings in the modelling phase.

Secondly, different methods of regulation of the cooling unit tested to improve the MT thermal behaviour were presented, namely fixed regulation and gradient regulation. Fixed regulation dramatically reduced the thermally induced displacements at the TCP compared to the non-cooled state. However, the results carried out on the test bed representing a 3-axis vertical milling machine confirmed that thermally induced displacements at the TCP 
decreased even further. The main deformation in Z-direction was suppressed below the other coordinates $X$ and $Y$ and in comparison with the non-cooled state, the gradient regulation method improved thermal error by two orders of magnitude.

The fluid cooling systems of MT are vital for the development of high precision MT due to control of their thermal behaviour, which generally deteriorates MT accuracy and consequently the resulting workpiece accuracy. As fluid cooling systems have significant impacts on resulting MT thermal errors likewise on thermal error compensation models, it seems worthwhile to focus further research on related issues.

\section{ACKNOWLEDGMENTS}

The authors would like to acknowledge funding support from the Czech Ministry of Education, Youth and Sports under the project CZ.02.1.01/0.0/0.0/16_026/0008404 "Machine Tools and Precision Engineering” financed by the OP RDE (ERDF). The project is also co-financed by the European Union.

\section{REFERENCES}

[1] MAREŠ M., HOREJŠ O., 2017, Modelling of Cutting Process Impact on Machine Tool Thermal Behaviour Based on Experimental Data, Procedia CIRP, 58, 152-157.

[2] BRYAN J., 1990, International Status of Thermal Error Research (1990), CIRP Annals - Manufacturing Technology, 39/2, 645-656.

[3] WEGENER K., MAYR J., MERKLEIN M., BERENS B.A., AOYAMA T., SULITKA M., FLEISCHER J., GROCHE P., KAFTANOGLU B., JOCHUM N., MOEHRING H-CH., 2017, Fluid Elements in Machine Tools, CIRP Annals - Manufacturing Technology, 60, 611-634.

[4] MAYR J., JEDRZEJEWSKI J., UHLMANN E., DONMEZ M.A., KNAPP W., HÄRTIG F., WENDT K., MORIWAKI T., SHORE P., SCHMITT R., BRECHER CH.,WÜRZ T., WEGENER K., 2012, Thermal Issues in Machine Tools, CIRP Annals - Manufacturing Technology, 61, 771-791.

[5] HORNYCH J., HOREJŠ O., 2012, The Adaptive Cooling Control of a Ball Screw Feed Drive, Proceedings of the 12th euspen International Conference, Stockholm, euspen.

[6] HOREJS̆ O., BÁRTA P., HORNYCH J., 2008, Modeling of Thermal Processes in a Cooled Ball Screw Feed Drive, MATAR 2008 - Proceedings of Part 1: Drives \& Control, Design, Models \& Simulation, Prague, SpOS, 147-152, ISBN 978-80-903421-9-4.

[7] HELlMiCH A., GLANZEL J., PIERER A., 2018, Analysing and Optimizing the Fluidic Tempering of Machine Tool Frames, CIRP Sponsored Conference on Thermal Issues in Machine Tools, Dresden, 195-210, ISBN 978-395735-085-5.

[8] POPKEN J., SHABI L., WEBER J., 2018, System Modelling and Control Concepts of Different Cooling System Structures for Machine Tools, CIRP Sponsored Conference on Thermal Issues in Machine Tools, Dresden, 93-106, ISBN 978-3-95735-085-5.

[9] TONNELLIER X., MORANTZ P., SHORE P., COMLEY P., 2010, Precision Grinding for Rapid Fabrication of Segments for Extremely Large Telescopes Using the Cranfield BoX, SPIE Astronomical Telescopes and Instrumentation: Observational Frontiers of Astronomy for the New Decade, 773905.

[10] BÁRTA P., HORNYCH J., HOREJŠ O., 2008, Active Control of a Machine Tool Cooling System, Proceedings of the 10th anniversary international conference of the EUSPEN, Zürich, 384-388.

[11] HORNYCH J., BÁRTA P., MAREŠ, M., 2009, Thermomechanical Transfer Functions and Control of a Machine Tool Cooling System, Modern Machinery (MM) Science Journal, 96-97.

[12] BÁRTA P., HOREJŠ O., HORNYCH J., VYROUBAL J., 2007, Thermal Transfer Function Based Control Method of a Machine Tool Cooling System, Proceedings of the Topical Meeting: Thermal Effects in Precision Systems. Maastricht, the Netherlands, euspen, 16-18.

[13] SHI X., ZHU K., WANG W., FAN L., GAO J., 2018, A Thermal Characteristic Analytic Model Considering Cutting Fluid Thermal Effect for Gear Grinding Machine Under Load, The International Journal of Advanced Manufacturing Technology, 99, 1755-1769. 
[14] BRYAN J., CLOUSER R., MCCLURE E., 1968, Expansion of a Cutting Tool During Chip Removal, CIRP Annals, $16,49-51$.

[15] JEDRZEJEWSKI J., KWASNY W., 2011, Study on Reducing Energy Consumption in Manufacturing Systems, Journal of Machine Engineering, 11/3, 7-20.

[16] CHEN J. S., 1996, A Study of Thermally Induced Machine Tool Errors in Real Cutting Conditions, Int. J. Mach. Tools Manuf., 36/12, 1401-1411.

[17] MAYR J., GEBHARDT M., MASSOW B.B., WEIKERT S., WEGENER W., 2014, Cutting Fluid Influence on Thermal Behavior of 5-Axis Machine Tools, Procedia CIRP, 14, 395-400.

[18] FRASER S., ATTIA M.H., OSMAN M.O.M., 1998, Modeling, Identification and Control of Thermal Deformation of Machine Tool Structures, Part 1: Concept of Generalized Modeling, ASME J. Manuf. Sci. Eng., 120/3, 623-631.

[19] BRECHER C., HIRSCH P., WECK M., 2004, Compensation of Thermo-Elastic Machine Tool Deformation Based on Control Internal Data, CIRP Annals - Manufacturing Technology, 53/1, 299-304.

[20] YANG H., NI J., 2003, Dynamic Modeling for Machine Tool Thermal Error Compensation, Journal of Manufacturing Science and Engineering, 125, 245-254.

[21] HOREJŠ O., MAREŠ M., KOHÚT P., BÁRTA P., HORNYCH J., 2010, Compensation of Machine Tool Thermal Errors Based on Transfer Functions, MM Science Journal, 2010/1, 162-165.

[22] MAYR J., BLASER P., RYSER A., HERNÁNDEZ BECERRO P., 2018, An Adaptive Self-Learning Compensation Approach for Thermal Errors on 5-Axis Machine Tools Handling an Arbitrary Set of Sample Rates, CIRP Annals Manufacturing Technology, 67/1, 551-554.

[23] FRASER S., ATTIA M.H., OSMAN M.O.M., 1998, Modeling, Identification and Control of Thermal Deformation of Machine Tool Structures, Part 2: Generalized Transfer Functions, ASME J. Manuf. Sci. Eng., 120/3, 632-639.

[24] LJUNG L., 2015, System Identification Toolbox ${ }^{\mathrm{TM}}$ User's Guide, The MathWorks, https://www.mathworks.com/ help/pdf_doc/ident/index.html.

[25] International standard ISO 230-3, Test Code for Machine Tools - Part 3: Determination of Thermal Effects, 2007, Genf, Switzerland.

[26] HOREJŠ O., MAREŠ M., HORNYCH J., 2014, A General Approach to Thermal Error Modelling of Machine Tools, Machines et usinage à grande vitesse (MUGV), Clermont Ferrand, France.

[27] MAREŠ M., HOREJŠ O., HAVLÍK L., 2020, Thermal Error Compensation of a 5-Axis Machine Tool Using Indigenous Temperature Sensors and CNC Integrated Python Code Validated with a Machined Test Piece, Precision Engineering [article in press], https://doi.org/10.1016/j.precisioneng.2020.06.010.

[28] HOREJŠ O., MAREŠ M., NOVOTNÝ L., 2012, Advanced Modelling of Thermally Induced Displacements and Its Implementation into Standard CNC Controller of Horizontal Milling Center, Procedia CIRP, 4/1, 67-72, ISSN $2212-8271$.

[29] https://www.industrialheating.com/articles/93936-methods-of-cooling-an-induction-process.

[30] MAREŠ M., HOREJŠ O., HORNYCH J., KOHÚT P., 2011, Compensation of Machine Tool Angular Thermal Errors using Controlled Internal Heat Sources, Journal of Machine Engineering, 11/4, 78-90, ISSN $1895-7595$. 